\title{
A NOTE ON SUBSEQUENCES
}

\section{R. CREIGHTON BUCK}

It is well known that a sequence is convergent if all of its subsequences are convergent. The purpose of this note is to show that this may be extended to a result of great generality.

THEOREM. A sequence is convergent if there exists a regular matrix summability method $T$, which sums every subsequence of the given sequence.

Thus, for example, if every subsequence of a given sequence is Cesàro summable of any order, then the sequence is convergent. The general theorem depends upon the following well known result of H. Steinhaus. ${ }^{1}$

LemMa. For any regular summability method $T$, given by the matrix $\left(A_{n m}\right)$, there exists a sequence of 0 's and 1's not summable $T$.

To establish the theorem, we suppose that the given sequence $\left\{S_{n}\right\}$ is divergent; we then show that, for any $T$, we can choose a subsequence $\left\{S_{r_{n}}\right\}$ not summable $T$. We may obviously restrict ourselves to bounded sequences. Set $S_{n}^{\prime}=\left(S_{n}-\lim \inf S_{n}\right) /\left(\lim \sup S_{n}-\lim \inf S_{n}\right)$. We observe that $\lim \inf S_{n}^{\prime}=0, \lim \sup S_{n}^{\prime}=1$, so that we may choose two disjoint subsequences

$$
\left\{S_{\alpha_{n}}^{\prime}\right\} \text { and }\left\{S_{\beta_{n}}^{\prime}\right\}
$$

which converge to 1 and 0 respectively.

We next construct a "replica" $\left\{S_{n}^{*}\right\}$ of the sequence $\left\{S_{n}^{\prime}\right\}$ by defining

$$
S_{n}^{*}=\left\{\begin{array}{lll}
1 & \text { if } n=\alpha_{k} & \text { for some } k \\
0 & \text { if } n=\beta_{k} & \text { for some } k \\
S_{n}^{\prime} \text { otherwise. } &
\end{array}\right.
$$

To justify the use of the term replica, we observe that $\left\{S_{n}^{*}\right\}$ and $\left\{S_{n}^{\prime}\right\}$ have the same limit points, that $\lim \left(S_{n}^{\prime}-S_{n}^{*}\right)=0$, and that in general the two sequences behave alike.

Among the terms of $\left\{S_{n}^{*}\right\}$, there are an infinite number of 1 's and of 0 's; by the Steinhaus Lemma, for any $T$, we can choose a subse-

Presented to the Society, October 30, 1943; received by the editors April 16, 1943.

${ }^{1}$ Hugo Steinhaus, Kitka slow o uogolnieniu pojecia granicy (Some remarks on the generalization of limit), Prace Matematyczno-Fizyczne vol. 22 (1911) pp. 121-134 (p. 129). 
quence $\left\{S_{r_{n}}^{*}\right\}$ which is not summable by the regular method $T$. Since $S_{n}^{\prime}=S_{n}^{*}+\theta_{n}$ where $\theta_{n}$ is a null sequence, $\left\{S_{r_{n}}^{\prime}\right\}$ is not summable $T$; thus, $\left\{S_{r_{n}}\right\}$ is a subsequence of the original sequence, and is not summable by the method $T$.

The theorem just proved may be stated in the form of a general Tauberian theorem-admittedly difficult to apply!

THEOREM. $A$ sequence $\left\{S_{n}\right\}$, summable by a regular matrix method $T$, is convergent if and only if each of its subsequences is also summable $T$.

As a corollary, we may obtain the following result for series:

COROLLARY. The series $\sum a_{n}$ is convergent if there exists a regular matrix summability method $T$, which sums every series formed from the given one by bracketing blocks of terms.

For, the partial sums of a bracketed series form a subsequence of the partial sums of the original series.

In closing, we note that the restriction to matrix methods is not essential, for the theorem is also true for Abel summability. However, it is apparent that it is not true for the Banach-Steinhaus generalized limit, which sums all bounded sequences. ${ }^{2}$

Society of Fellows,

HARVARD UNIVERSITY

2 S. Banach, Théorie des opérations linéaires, p. 34. 